Brit. Heart F., 1967, 29, 239.

\title{
Reversed Mitral Diastolic Gradient in Aortic Incompetence
}

\author{
G. C. OLIVER, Jr., N. GAZETOPOULOS, AND D. C. DEUCHAR \\ From the Cardiac Department, Guy's Hospital, London S.E.1
}

Information about the hæmodynamics of severe aortic regurgitation, though a subject of much interest, is still scanty (Segal, Harvey, and Hufnagel, 1956; Dodge, Sandler, and Evans, 1960; Meadows et al., 1963). Up to 1964, only seven cases of aortic regurgitation in which there was a reversed mitral valve gradient in late diastole could be found by Rees et al. (1964) in their review of the published reports. The purpose of this paper is to report six additional cases in which we believe this phenomenon was present, and to draw attention to certain features of this situation.

\section{SuBJECTS AND METHODS}

All patients had significant aortic incompetence, either as a solitary lesion, or combined with other lesions such as mild aortic stenosis, mitral or tricuspid valve disease.

Cardiac catheterization was carried out in the fasting state with papaveretum, $20 \mathrm{mg}$., and hyoscine methobromide, $0.4 \mathrm{mg}$., given parenterally as premedication in most cases. Occasionally promethazine, $25 \mathrm{mg}$., was given orally, if further sedation was required. Right heart catheterization was performed in a standard manner, and wedge pressures were usually obtained as representative of left atrial pressure. Only wedge pressure tracings that showed a recognizable atrial wave form were accepted for final analysis, and a particular effort was made to exclude "damped" wedge pressure tracings. We have also accepted only tracings in which the left ventricular diastolic pressure exceeded the wedge pressure by at least $5 \mathrm{~mm}$. $\mathrm{Hg}$. In one case, the left atrial pressure was measured directly after a catheter had been passed transseptally according to the technique of Brockenbrough and Braunwald (1960). Left ventricular pressures were measured by passing a P.E. 160 cathether retrogradely from a femoral artery into the left ventricle, using the technique of Seldinger (1953). All left ventricular and wedge pressures, and left ventricular and left atrial pressures, were recorded simultaneously photographically, using inductance gauges. Particular care was taken to ensure that zero pressure levels were

Received September 1, 1965. comparable when simultaneous pressures were recorded. The gauges were standardized before and after each catheterization using a calibrated mercury column.

For determination of cardiac output the Fick method was used, oxygen consumption being determined by spirometry and blood oxygen contents by spectrophotometry. Estimates of the degree of aortic incompetence were made by using a slight modification of Braunwald's technique (Braunwald and Morrow, 1958). A Cambridge ear-piece was placed on the left ear, and dye curves were recorded after aortic injection of 0.8 per cent indigo carmine. The first injection was made at the origin of the left common carotid artery and subsequent injections were made at measured distances distally down the aorta. A positive dye curve is indicated by a prompt deflection (within a few seconds after the injection). This indicates that dye has regurgitated from the point of injection at least as far as the origin of the left common carotid artery, and is carried to the left ear by the next heart beat. A negative dye curve does not show this prompt appearance. In our laboratory, as a rough estimate of the degree of aortic incompetence, aortic dye curves are interpreted as follows: mild aortic incompetence-positive at $0-10 \mathrm{~cm}$.; moderate aortic incompetence-positive at $10-20 \mathrm{~cm}$.; severe aortic incompetence-positive at more than $20 \mathrm{~cm}$. distal. Phonocardiograms were recorded on a 5-channel photographic recorder, at a paper speed of $80 \mathrm{~mm}$./second.

\section{CASe REPorts}

Case 1. This 29-year-old man had rheumatic fever when he was 15 years old. He was well, however, until he was 28 , when he developed dyspnœe and palpitations, and on examination was found to have aortic incompetence. Examination revealed a blood pressure of 140/40 $\mathrm{mm} . \mathrm{Hg}$, and a collapsing pulse. Left ventricular enlargement was present with the apex at the anterior axillary line in the 6th left intercostal space. A loud aortic diastolic murmur was present. At the apex, the first sound was variously described as diminished, normal, or increased. A soft apical pansystolic murmur was present, and an apical third heart sound was noted. Electrocardiograms showed left ventricular hypertrophy 


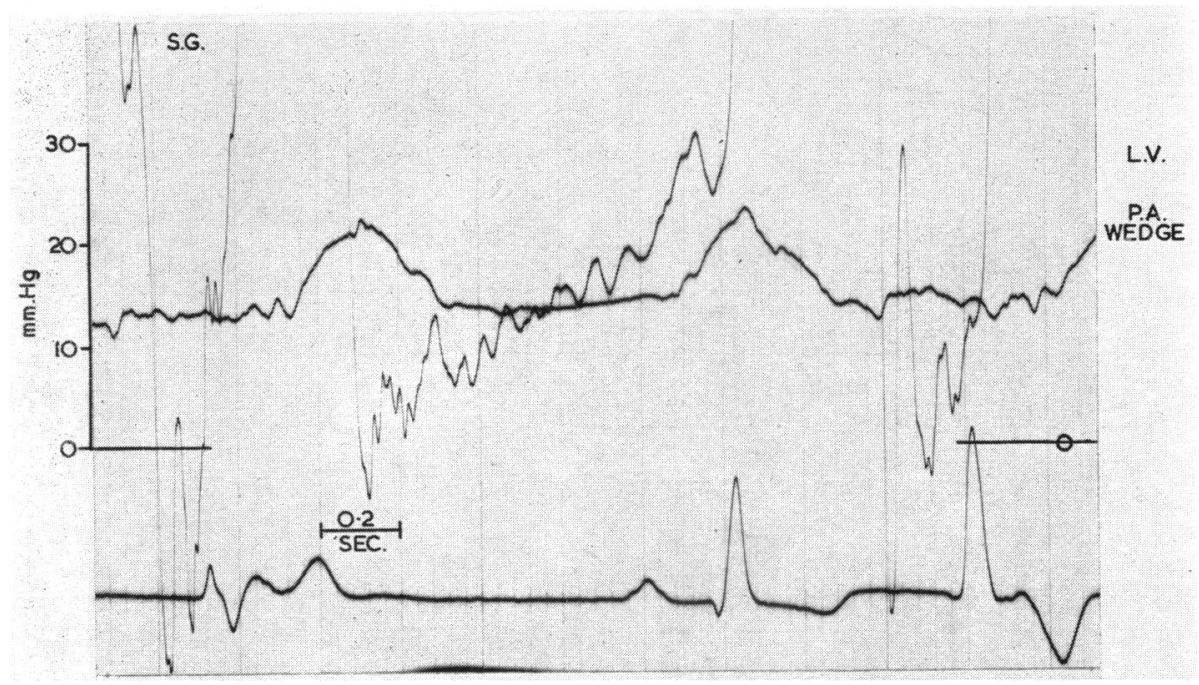

Fig. 1.-Simultaneously recorded left ventricular and pulmonary wedge pressures in Case 1. The bottom record in this and all subsequent illustrations (except Fig. 6) is a simultaneously recorded electrocardiogram. Note the reversed gradient in late diastole.

and a chest radiograph indicated left ventricular enlargement with possible left atrial enlargement.

At cardiac catheterization, the cardiac output was 3.81./ $\min$. $\left(2 \cdot 11 . / \mathrm{min} . / \mathrm{m}^{2}\right)$, wedge pressure $a 24, x 13, v 16, y 13$ $\mathrm{mm}$. $\mathrm{Hg}$, LV 130/0 mm. $\mathrm{Hg}$, end-diastolic $31 \mathrm{~mm}$. $\mathrm{Hg}$, and aorta $130 / 50 \mathrm{~mm}$. $\mathrm{Hg}$ (mean 80). Aortic dye curves were positive at $25 \mathrm{~cm}$. and negative at $28 \mathrm{~cm}$. A simultaneous left ventricular wedge tracing is shown in Fig. 1.

Case 2. This 46-year-old man had chorea at the age of 5, and rheumatic fever at 42 . He was enlisted in the army when he was 22 , but discharged after 6 months because of dyspncea while carrying heavy loads. He remained active, however, and for years led a normal life. He was admitted following the sudden onset of pain and numbness in his legs, and was found to have an aortic embolus. He was treated medically and the circulation to the legs improved. On examination his blood pressure was $120 / 70 \mathrm{~mm}$. Hg. The heart was enlarged with the apex at the anterior axillary line in the 5th left intercostal space. At the apex, a systolic thrill and loud pansystolic murmur were noted. An opening snap was present followed by a moderate length mitral diastolic murmur. In the aortic area a short systolic ejection murmur and a loud aortic regurgitant murmur were present. The first heart sound was described by one observer as increased. A cardiogram on admission showed atrial fibrillation, a recent diaphragmatic wall myocardial infarction, and possible left ventricular hypertrophy. A previous record taken in January 1964 showed atrial fibrillation and left ventricular hypertrophy. Chest radiograph showed an enlarged left ventricle and atrium, and Kerley's lines. On screening, increased aortic pulsations consistent with aortic incompetence were noted.

After he recovered, cardiac catheterization revealed a cardiac output of $1 \cdot 81$. $/ \mathrm{min}$. $\left(1 \cdot 31 . / \mathrm{min} . / \mathrm{m}^{2}{ }^{2}\right)$. The wedge pressure was $32 / 21 \mathrm{~mm}$. $\mathrm{Hg}$, LV $155 / 12 \mathrm{~mm}$. $\mathrm{Hg}$, enddiastolic 35 , brachial artery $125 / 75 \mathrm{~mm}$. $\mathrm{Hg}$ (mean 85 ). Aortic dye curves were positive at $10 \mathrm{~cm}$. and negative at $12 \mathrm{~cm}$. A small $(2-3 \mathrm{~mm}$. $\mathrm{Hg})$ diastolic gradient was present between the right atrium and right ventricle. Simultaneous left ventricular wedge pressures are shown in Fig. 2.

Case 3. This 14-year-old schoolboy had a heart murmur noted on a routine school examination at the age of 5. He was examined at this time and told he had a "hole in the heart". He was little troubled by this and led an asymptomatic active life, which included playing football.

On examination at the age of 14 , the blood pressure was $150 / 70 \mathrm{~mm}$. Hg. The left ventricle was enlarged. In the aortic area there was a systolic thrill and a loud ejection murmur. A loud aortic regurgitant murmur was present as well. The first sound was inaudible. Electrocardiogram and chest radiograph showed left ventricular hypertrophy. The ascending aorta was prominent. At cardiac catheterization the wedge pressure was $30 / 20 \mathrm{~mm} . \mathrm{Hg}$, left ventricular $135 / 0 \mathrm{~mm}$. $\mathbf{H g}$, end-diastolic $26 \mathrm{~mm}$. Hg, aorta $125 / 63 \mathrm{~mm}$. Hg. Aortic dye curves were positive at $10 \mathrm{~cm}$. and negative at $12 \mathrm{~cm}$.

Case 4. This 42-year-old man was in hospital for 12 months with rheumatic fever when he was 30 . He recovered, and thereafter did fairly well. However, at the age of 37 he developed palpitations and was found to have an enlarged heart. His condition gradually worsened and he stopped working at the age of 39 . Over the next several years he had various hospital admissions for suspected endocarditis, but the diagnosis was never established; he was transferred to this hospital to decide whether an operation would be advisable. 


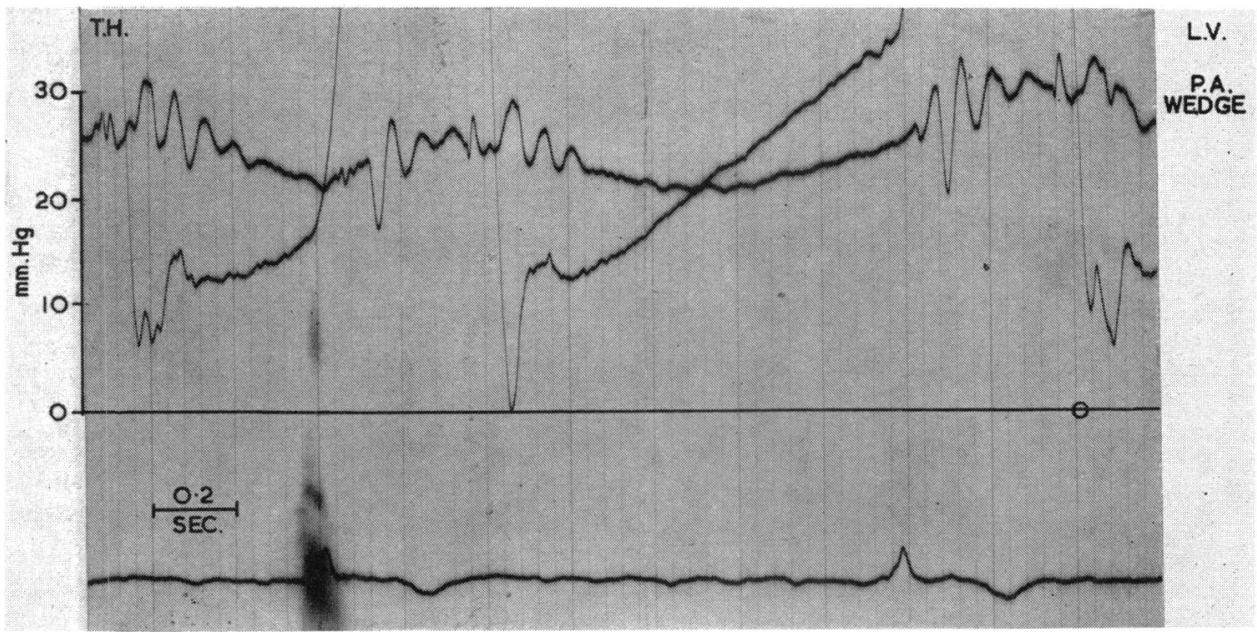

Fig. 2.-Left ventricular and simultaneous pulmonary wedge tracings in Case 2. Note the characteristic " $\mathrm{X}$ " formed by the rising left ventricular diastolic pressure and the wedge pressure. Atrial fibrillation is present.

On examination the blood pressure was $180 / ? 0 \mathrm{~mm}$. $\mathrm{Hg}$, with collapsing pulses and Corrigan's sign in the neck. A thrill was present in the carotid vessels. Clinically, the left ventricle was enlarged and there was a suggestion of right ventricular enlargement. In the aortic area an ejection murmur was present followed by a moderately loud regurgitant murmur. An apical pansystolic murmur was present followed by a third heart sound. The first heart sound was described as normal. An electrocardiogram revealed sinus rhythm with firstdegree atrio-ventricular block ( $P-R$ interval $=0.34$ sec.) and left ventricular hypertrophy. Chest radiograph also showed left ventricular hypertrophy and possible left atrial enlargement.
At cardiac catheterization the cardiac output was $2 \cdot 21 . / \mathrm{min}$. $\left(1 \cdot 31 . / \mathrm{min} . / \mathrm{m}^{2}\right)$. Pressures were as follows: pulmonary wedge $32 / 14 \mathrm{~mm}$. $\mathrm{Hg}$, left ventricular $145 / 20$ $\mathrm{mm}$. $\mathrm{Hg}$, end-diastolic pressure $26 \mathrm{~mm}$. $\mathrm{Hg}$, and aorta $145 / 45 \mathrm{~mm}$. $\mathrm{Hg}$ (mean 65). Aortic dye curves were positive at $25 \mathrm{~cm}$., questionably positive at $30 \mathrm{~cm}$., and negative at $35 \mathrm{~cm}$. Fig. 3 shows the simultaneously recorded left ventricular and wedge pressures.

Case 5. This 23-year-old man had rheumatic fever at the age of 7 and again at the age of 16, after which he developed severe aortic incompetence; however, he remained well until he was 23 , when he developed bacterial endocarditis, due to Staphylococcus aureus. He

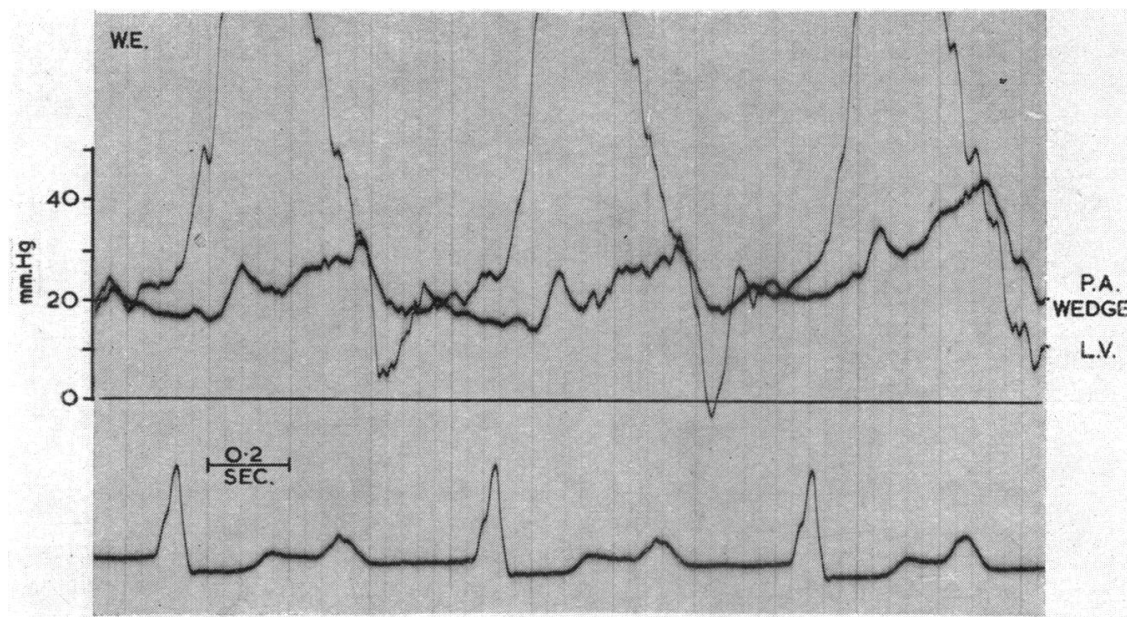

Fig. 3.-Simultaneous left ventricular and pulmonary wedge pressures in Case 3. Note the presence of first degree A-V block, and the late diastolic gradient which is not affected by the early "a" wave. 
was treated with antibiotics, but failed to improve, and several weeks after the onset of illness had an embolus to the left leg and was transferred to this hospital. On examination he was ill with a temperature of $103^{\circ} \mathrm{F}$. $\left(39 \cdot 4^{\circ} \mathrm{C}\right.$.). The blood pressure was $160 / 25 \mathrm{~mm}$. $\mathrm{Hg}$. The pulses were collapsing and capillary pulsations were present. The left ventricle was enlarged. At the apex the first heart sound was described as normal, followed by a loud pansystolic murmur associated with a thrill. In the aortic area an ejection murmur was present followed by a loud regurgitant murmur. Electrocardiogram and chest radiograph showed left ventricular hypertrophy. Blood cultures were sterile. When his condition was improved following medical treatment, cardiac catheterization was performed. The cardiac output was $3.71 . / \mathrm{min}$. $\left(2 \cdot 21 . / \mathrm{min} . / \mathrm{m}^{2}\right)$. Pressures were as follows: left atrium $a 16, x 13, v 17, y 15$; left ventricle $120 / 0 \mathrm{~mm}$. $\mathrm{Hg}$, end-diastolic $31 \mathrm{~mm}$. $\mathrm{Hg}$; aorta $120 / 55$ $\mathrm{mm}$. $\mathrm{Hg}$ (mean 75). Dye curves were positive at $15 \mathrm{~cm}$., and doubtfully positive at $20 \mathrm{~cm}$.

Case 6. This 61-year-old woman was admitted to this hospital for evaluation of dizzy spells and breathlessness of two years' duration. There was no past history of heart disease or rheumatic fever, and she had been well until the onset of the above symptoms, and when seen at that time, the diagnosis of aortic valve disease was made. During the next two years the dizzy spells and breathlessness occurred from time to time, but were not associated with syncope, orthopnœe, or paroxysmal nocturnal dyspnœa, and in between these episodes she had a normal exercise tolerance.

On examination, the blood pressure was $155 / 55 \mathrm{~mm}$. $\mathrm{Hg}$, and the pulse was irregular with a rate of 50-70 beats a minute. Arterial pulses were bisferiens. The jugular venous pulse was normal. The heart was enlarged, with the apex located at the anterior axillary line in the sixth left intercostal space. In the aortic area, a prominent ejection murmur was noted. An early diastolic murmur of aortic incompetence was noted in the aortic area and along the left sternal border. The heart sounds were quiet. An electrocardiogram on admission showed atrial fibrillation with an irregular ventricular rate of 45 a minute. Complete right bundle-branch block was present, along with evidence of digitalis effect. Chest radiograph showed some cardiomegaly, but with a normal-sized aortic root.

At cardiac catheterization the cardiac output was 3.51./ $\mathrm{min}$. $\left(2 \cdot 1 \mathrm{l} . / \mathrm{min} . / \mathrm{m}^{2}\right)$. The wedge pressure was $26 / 16$ $\mathrm{mm}$. $\mathrm{Hg}$, left ventricle $200 / 13 \mathrm{~mm}$. $\mathrm{Hg}$, end-diastolic 21 $\mathrm{mm}$. Hg; aorta 200/55 mm. Hg. Dye curves were positive at $10 \mathrm{~cm}$. and negative at $12 \mathrm{~cm}$.

\section{Discussion}

A reversed mitral diastolic gradient with attendant premature mitral valve closure is widely held to be a rare phenomenon (Meadows et al., 1963; Rees et al., 1964). In addition, Rees et al. (1964) state that all previously reported cases have had aortic incompetence of such severity that there was equili- bration of left ventricular and aortic diastolic pressures. We have collected the present group during the past year by actively searching for this phenomenon in patients with aortic incompetence who were catheterized in our laboratory.

Our current technique of study usually provides us with simultaneous pulmonary wedge and left ventricular pressures. A comment should be made concerning the use of wedge pressure as an indication of left atrial pressure. Although some authors have found wedge pressure unreliable at times (Murphy, 1958; Bernstein et al., 1960; Linden, 1963; Linden and Allison, 1963), others have stressed the accuracy of wedge pressures as a measurement of left atrial pressure (Dow and Gorlin, 1950; Björk, Malmström, and Uggla, 1953; Connolly et al., 1953b; Epps and Adler, 1953; Werkö et al., 1953; Connolly et al., 1953a ; Björk, Malmström, and Uggla, 1954; Connolly, Kirklin, and Wood, 1954; Luchsinger, Seipp, and Patel, 1962). In a study of patients with atrial septal defect, in whom the left atrial pressure could be measured by passing a catheter into the left atrium, or mitral stenosis, or lung tumour in which left atrial and wedge pressures were measured at the time of operation, Connolly et al. (1954) found an excellent correlation between wedge and simultaneously recorded left atrial pressures. In their study the maximum difference between the two was $6 \mathrm{~mm}$. $\mathrm{Hg}$. In a similar study in patients with mitral stenosis in which simultaneous left atrial and wedge pressures were recorded, the average difference between the two was less than $1 \mathrm{~mm}$. $\mathrm{Hg}$, with a maximum difference of $5 \mathrm{~mm}$. Hg (Connolly et al., 1953b). Slightly better agreement was noted by Epps and Adler (1953) who measured left atrial pressure via the transbronchial route. - In their study the maximum difference between left atrial and wedge pressures was $3 \mathrm{~mm}$. $\mathrm{Hg}$ during systole, $4 \mathrm{~mm}$. $\mathrm{Hg}$ during diastole, with a mean difference of $1 \mathrm{~mm}$. Hg. They noted that wedge pressure waves were delayed 0.02 to $0.08 \mathrm{sec}$. in relation to left atrial waves.

It is our opinion that while direct left atrial pressure measurements are to be preferred when available, it is still possible to draw valid conclusions if wedge pressure tracings are carefully scrutinized to ensure tracings are not damped or are not recorded from incompletely wedged catheters. In the latter event, of course, there would be a falsely high pressure, so that if the left ventricular end-diastolic pressure exceeds this, then it must surely exceed the left atrial pressure. Fig. 4 shows simultaneously recorded left ventricular and wedge tracings in a patient with pure aortic stenosis with no evidence of aortic incompetence. It can be noted that there 


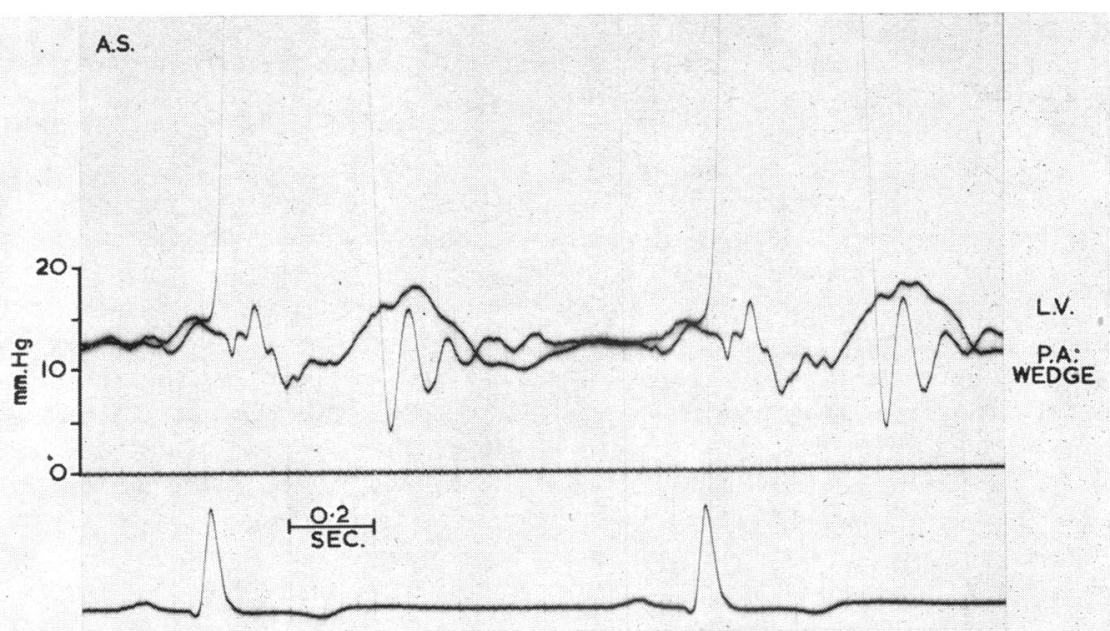

Fig. 4.-Simultaneously recorded left ventricular and pulmonary wedge pressures in a 23-year-old man with congenital valvar aortic stenosis and no clinical evidence of aortic incompetence. Note the close agreement during late diastole between the two pressures.

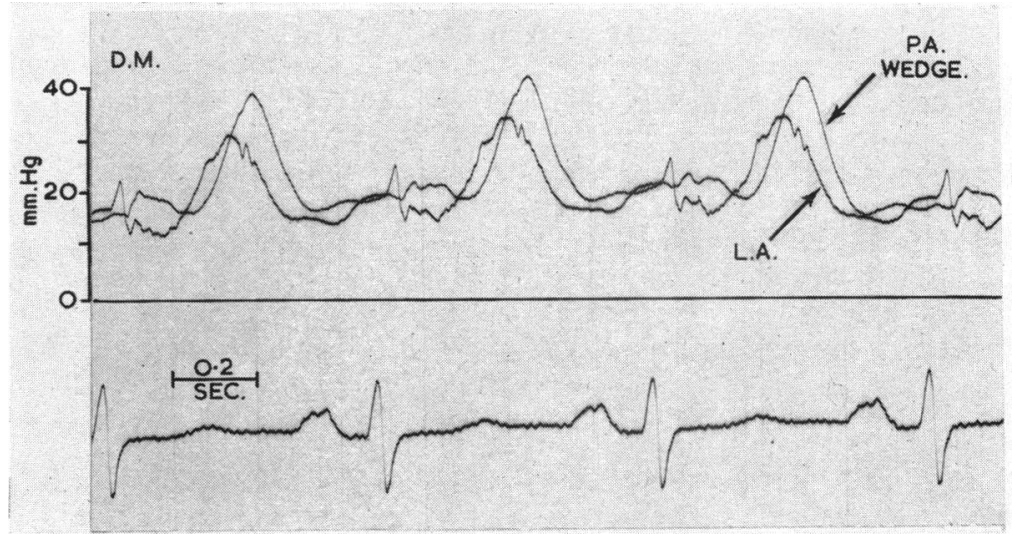

FIG. 5.-Simultaneously recorded left atrial and pulmonary artery wedge pressures in a 44-year-old woman with mitral regurgitation. Note the close agreement between the two pressures at the end of diastole. During systole, the wedge pressure is slightly higher than the left atrial pressure.

is no reversed mitral diastolic gradient in this case. Fig. 5 shows simultaneously recorded wedge and left atrial pressures in a woman with severe mitral incompetence. It can be noted that there is close similarity between the two pressures throughout the cardiac cycle, and that the two are substantially the same at the end of diastole.

In the cases of reversed mitral gradient thus far reported, simultaneous pressures were obtained in only one case (Colvez et al., 1959) whereas nonsimultaneous pressures were obtained in the others, this necessitating replotting of the pressures. The left ventricular end-diastolic pressure exceeded the left atrial or wedge pressure by $10-40 \mathrm{~mm}$. $\mathrm{Hg}$ in previously reported cases. Our data reveal a differ- ence of $5-15 \mathrm{~mm}$. $\mathrm{Hg}$ between these pressures. It is perhaps because we have suitable simultaneous pressure records available that the phenomenon of a reversed gradient has been found more frequently in our material. In particular we have noticed that equilibration of the aortic and left ventricular pressure at the end of diastole is not essential for its production, as suggested by Rees et al. (1964). We also have noted that when there is a large atrial " $a$ " wave it is sometimes difficult to be certain whether or not the left ventricular end-diastolic pressure exceeds the left atrial or wedge pressure; as Fig. 2 shows, when atrial fibrillation is present it is much easier to be certain. All previously published cases have had either sinus rhythm or a rhythm that could 
not be determined from the report (Wright, Toscano-Barboza, and Brandenburg, 1956; Colvez et al., 1959; Kelly, Morrow, and Braunwald, 1960; Meadows et al., 1963; Rees et al., 1964). Fig. 2 also shows that when both atrial fibrillation and mitral stenosis are present, a very characteristic " $X$ " is made by the falling wedge pressure on the one hand and the rising left ventricular diastolic on the other. In this circumstance, the demonstration of a reversed gradient is particularly facilitated. Again, as Fig. 3 shows, when there is a prolonged P-R interval, the left atrial " $a$ " wave occurs much earlier, and thus does not obscure events at the very end of diastole. The coexistence of mitral valve obstruction with aortic incompetence may possibly facilitate the development of a reversed gradient. The presence of atrial fibrillation may also do so when long diastolic intervals occur. Long diastolic intervals are, in these patients, of little or no physiological benefit because once the left ventricular diastolic pressure exceeds the left atrial pressure, no further mitral flow can occur. The diastolic time during which mitral flow can occur is limited, and aortic incompetence with a reversed mitral diastolic gradient in effect produces a "physiologic mitral stenosis". In this situation, it seems likely that the time available during which mitral flow can occur may be nearly constant from beat to beat. If this were so, effective diastole could be increased only by an increase in heart rate, yielding more beats a minute. This may in part explain why patients with aortic incompetence tolerate bradycardia so poorly.
A puzzling feature in some of our cases is the report of normal first heart sounds, despite the finding of a reversed gradient. There are several possible explanations for this. First, the observer may have heard tricuspid closure of an ejection sound and incorrectly interpreted this as mitral closure. Secondly, whether mitral closure is premature or not depends in part on cycle length, for when diastole is short, enough time may not be available to allow a sufficient increase in left ventricular diastolic pressure to bring about premature mitral closure. Thus, at time of examination the patient may have a faster heart rate than when sedated for cardiac catheterization. In the latter circumstances, longer diastoles may permit the development of a reversed mitral gradient and premature mitral valve closure. Thirdly, some of our patients had atrial fibrillation. When this is present, there is a random selection of diastolic lengths. Fig. 6 shows a phonocardiogram from one such patient. It will be noted that the first heart sound is soft after long diastoles, and louder after short ones. The variability of first heart sound loudness during atrial fibrillation has been described before (Rytand, 1949). Although it can occur in atrial fibrillation without valvar disease, when aortic incompetence is added, there is an additional reason for a variable loudness of the first heart sound. In this circumstance, whether attention is concentrated on the occasional loud sound, or the soft ones, may well depend on the individual observer, and lead to a varying report on first sound loudness. Finally, recent studies by Shah et al. (1963) throw

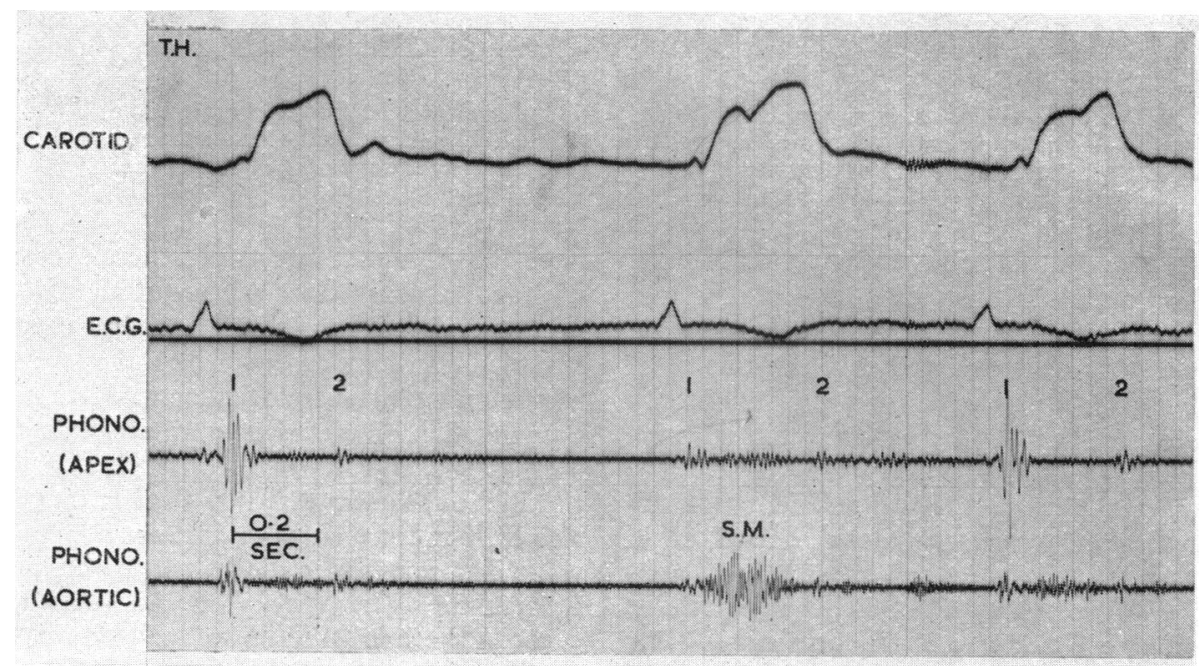

Fig. 6.-Phonocardiogram recorded on Case 2. Note the variable intensity of the first heart sound, louder after short diastoles. Atrial fibrillation is present. Carotid refers to an external carotid artery pressure pulse. Aortic refers to the second right interspace along the right sternal border. 
serious doubt on the hypothesis that the first heart sound is caused by mitral valve closure. If this is so, then premature mitral valve closure is in no way incompatible with the presence of a first heart sound of normal intensity.

\section{SUMMARY}

Hæmodynamic and clinical data are presented on six patients who were found to have a reversed mitral diastolic gradient. These patients all had significant aortic incompetence either alone or combined with other lesions such as mild aortic stenosis, mitral or tricuspid valve disease. In contrast to previously reported cases we have found that this phenomenon can occur without equilibration of aortic and left ventricular pressure during diastole. Several patients had either atrial fibrillation or first degree heart block. These features appear to facilitate recognition of a reversed mitral diastolic gradient. Although this phenomenon should theoretically lead to a soft first heart sound, this was not always observed: the reasons for this are discussed.

The authors are very grateful to Dr. Charles Baker for allowing us to study many of his patients. We are grateful for the help of Mr. John Gwynn in preparing the Figures.

One of us (G. C. O.) was supported by a U.S. Public Health Service Fellowship (5-F2-HE-19, 427-02) from the National Heart Institute.

\section{REFERENCES}

Bernstein, W. H., Fierer, E. M., Laszlo, M. H., Samet, P., and Litwak, R. S. (1960). The interpretation of pulmonary artery wedge (pulmonary capillary) pressures. Brit. Heart f., 22, 37.

Björk, V. O., Malmström, G., and Uggla, L. G. (1953). Left auricular pressure measurements in man. Ann. Surg., 138, 718.

$\longrightarrow, \frac{}{\text { " }}$, and $-(1954)$. Left atrial and pulmonary " pressure curves during Valsalva's experiment. Amer. Heart F., 47, 635.

Braunwald, E., and Morrow, A. G. (1958). A method for the detection and estimation of aortic regurgitant flow in man. Circulation, 17, 505.

Brockenbrough, E. C., and Braunwald, E. (1960). A new technic for left ventricular angiocardiography and transseptal left heart catheterization. Amer. F. Cardiol., 6, 1062.

Colvez, P., Alhomme, P., Samson, M., and Guedon, J. (1959). La pression de remplissage du ventricule gauche dans les grandes insuffisances aortiques. Ses relations avec l'allongement de la conduction auriculoventriculaire. Arch. Mal Cour, 52, 1369.
Connolly, D. C., Kirklin, J. W., and Wood, E. H. (1954). The relationship between pulmonary artery wedge pressure and left atrial pressure in man. Circulat. Res., 2, 434.

—, Lev, R., Kirklin, J. W., and Wood, E. H. (1953a). Pulmonary artery wedge pressures in mitral valve diseases; relationship to left atrial pressure. Fed. Proc., $12,28$.

—_, Tompkins, R. G., Lev., R., Kirklin, J. W., and Wood, E. H. (1953b). Pulmonary-artery wedge pressures in mitral valve disease; relationship to left atrial pressures. Proc. Mayo Clin., 28, 72.

Dodge, H. T., Sandler, H, and Evans, T. (1960). Observations on the hemodynamics of severe aortic insufficiency in man. Circulation, 22, 741.

Dow, J. W., and Gorlin, R. (1950). Pulmonary 'capillary' pressure as an index of left atrial mean pressure in dogs. Fed. Proc., 9, 33.

Epps, R. G., and Adler, R. H. (1953). Left atrial and pulmonary capillary venous pressures in mitral stenosis. Brit. Heart f., 15, 298.

Kelly, E. R., Morrow, A. G., and Braunwald, E. (1960). Catheterisation of the left side of the heart. New Engl. f. Med., 262, 162.

Linden, R. J. (1963). A comparison of gradients in the left atrial and pulmonary artery "wedge" pressure pulses. Clin. Sci., 25, 471.

- and Allison, P. R. (1963). The relationship between left atrial pressure and pulmonary artery "wedge" pressure in man. Clin. Sci., 25, 459.

Luchsinger, P. C., Seipp, H. W., Jr., and Patel, D. J. (1962). Relationship of pulmonary artery-wedge pressure to left atrial pressure in man. Circulat. Res., 11, 315.

Meadows, W. R., Van Praagh, S., Indreika, M., and Sharp, J. T. (1963). Premature mitral valve closure. A hemodynamic explanation for absence of the first sound in aortic insufficiency. Circulation, 28, 251.

Murphy, J. P. (1958). Inaccuracy of wedge pressure as an index of pulmonary capillary pressure. Circulation, 17, 199.

Rees, J. R., Epstein, E. J., Criley, J. M., and Ross, R. S. (1964). Hæmodynamic effects of severe aortic regurgitation. Brit. Heart F., 26, 412.

Rytand, D. A. (1949). The variable loudness of the first heart sound in auricular fibrillation. Amer. Heart f., 37, 187.

Segal, J., Harvey, W. P., and Hufnagel, C. (1956). A clinical study of one hundred cases of severe aortic insufficiency. Amer. F. Med., 21, 200.

Seldinger, S. I. (1953). Catheter replacement of the needle in percutaneous arteriography. A new technique. Acta radiol. (Stockh.), 39, 368.

Shah, P. M., Mori, M., MacCanon, D. M., and Luisada, A. A. (1963). Hemodynamic correlates of the various components of the first heart sound. Circulat. Res., 12, 386.

Werkö, L., Varnauskas, E., Eliaseh, H., Lagerlof, H., Senning, A., and Thomasson, B. (1953). Further evidence that the pulmonary capillary venous pressure pulse in man reflects cyclic pressure changes in the left atrium. Circulat. Res., 1, 337.

Wright, J. L., Toscano-Barboza, E., and Brandenburg, R. O. (1956). Left ventricular and aortic pressure pulses in aortic valvular disease. Proc. Mayo Clin., 31, 120. 